\title{
SAÚDE MENTAL: DO VELHO AO NOVO PARADIGMA - UMA REFLEXÃO
}

\author{
Mental Health: \\ From the Old to the New Paradigm - A Reflection \\ Salud Mental: \\ Del Viejo al Nuevo Paradigma - Una Reflexión
}

$\begin{array}{ll}\text { Marlene Gomes Terra } & \text { Dorotéa Loes Ribas } \\ \text { Fernanda Sarturi } & \text { Alacoque Lorenzini Erdmann }\end{array}$

\section{Resumo}

0 texto desenvolve idéias desencadeadas a partir de reflexões teóricas e das vivências das autoras diante da compreensão histórica da psiquiatria e alguns pontos chave da desinstitucionalização com o objetivo de vislumbrar possibilidades de um novo paradigma onde o ser humano possa ser visto como um cidadão em sofrimento e não mais como uma doença. Em decorrência das mudanças da área da psiquiatria, a enfermagem buscou inserir-se de maneira a oferecer uma assistência mais humanizada fundamentada nos princípios da Reforma Psiquiátrica. É necessário pensarmos as nossas práticas a partir de uma perspectiva humana, sensível, reflexiva, crítica, criativa reconhecendo a especificidade e a objetividade de cada ser humano com que interagimos. Portanto, a enfermagem necessita repensar os seus saberes e as suas práticas reavaliando sua atitude, postura, trabalho em grupo e ética.

Palavras-chave: Enfermagem Psiquiátrica. Saúde Mental. Desinstitucionalização.

\section{Abstract}

The text develops unchained ideas from theoretical reflections and the authors' experiences before the historical comprehension of the psychiatry and some desinstitucionalization key points with the objective of to glimpse possibilities of a new paradigm where the human being can be seeing as a citizen in suffering and no more as a person with a disease. Due to the changes in the area of psychiatry, the nursing searched a place in a way to offer a more humanized attendance based on the principles of the Psychiatry Reform. It is necessary to think about our practices under a human, sensitive, reflexive, critic and creative perspective recognizing the specificity and the objectivity of each human being which we interact with. Therefore, the nursing needs to rethink its knowledge and its practices revaluing its attitude, posture, work in group and ethics.

\section{Resumen}

El texto desenrolla ideas desencadenadas según reflexiones teóricas y de las experiencias de las autoras delante de la comprensión histórica de la psiquiatría y algunos puntos llaves de la desinstitucionalización, con objetivo de vislumbrar posibilidades de un nuevo paradigma donde el ser humano pueda ser visto como un ciudadano en sufrimiento y no más como una enfermedad. Según los cambios del área de psiquiatría, la enfermería buscó añadirse de manera a ofrecer una ayuda más humanizada basada en los principios de la Reforma Psiquiátrica. Es necesario que repensemos nuestra práctica según la perspectiva humana, sensible, reflexiva, crítica y creativa reconociendo la espeficidad y la objetividad de cada ser humano con el cual interaccionamos. Por lo tanto, la enfermería necesita repensar sus saberes y sus prácticas revaluando su actitud, postura, trabajo en equipo y con ética.

Palabras clave:

Enfermería Psiquiátria. Salud Mental. Desinstitucionalización
Keywords:

Psychiatric Nursing. Mental Health. Desinstitutionalization. 


\section{CONSIDERAÇÕES INICIAIS}

Hoje, refletindo sobre os pacientes que realizam acompanhamento nos diferentes serviços de saúde mental, nos deparamos ainda com inúmeros percalços a serem trabalhados e vencidos. A evolução histórica da psiquiatria e da sociedade possibilita percebermos a pessoa em sofrimento psíquico em diferentes contextos sociais e familiares dentro da assistência integral a este ser, mesmo que amparados pela Reforma Psiquiátrica Brasileira.

A reflexão sobre a psiquiatria leva-nos a pensar que esta é uma área na qual algumas pessoas comportam-se de um jeito bizarro e, às vezes nos assustam pela maneira como falam coisas desconexas e incoerentes. Podem ser incapazes de usar discernimento ou serem perseguidas por suas vozes. Conviver com pessoas que apresentam este comportamento não é fácil, principalmente quando manifestam atitudes agressivas e delirantes.

A doença mental por longo tempo foi caracterizada como uma falha que a pessoa apresentava em seu comportamento diante da sociedade, estando assim fora das expectativas esperadas para o convívio social. Inicialmente, pensava-se que as doenças mentais eram causadas por maus espíritos, magias ou por doenças físicas responsáveis por alterações na mente, observadas exclusivamente como fenômenos psicológicos e tendo suas causas desconhecidas.

Várias técnicas foram utilizadas com o intuito de curar o mal dos doentes, porém, as causas desses distúrbios não eram evidentes. Então, a fim de esclarecer esses comportamentos, o ser humano necessitou de uma ciência capaz de investigar o universo da mente. Essa investigação iniciou-se com o objetivo de explicar que as doenças tinham influências malignas e, portanto, eram tratadas pela feitiçaria, filósofos, magia ou pela religiosidade. Com o passar do tempo, outros se dedicaram a estudar esse fenômeno como médicos, artistas, sacerdotes, cientistas e mais tarde os especialistas em psiquiatria.

Embora considerada parte da Medicina e da Enfermagem, a psiquiatria era mantida de lado, deixando muitos doentes ao cuidado asilar, o qual estava fundamentado em princípios de vigilância e punição, e utilizava práticas terapêuticas como o eletrochoque e a contenção física. A psiquiatria não visava à cura, mas manter os pacientes reclusos em manicômios isolados do mundo e de seu cotidiano.

No decorrer da história, grandes estudiosos deram suas contribuições à psiquiatria, porém, à medida que a ciência progredia, o corpo humano foi se revelando como uma verdadeira máquina constituída de partes separadas e que funcionava mecanicamente. Essa visão levou-nos a aceitar o nosso corpo dissociado da mente, permitindo desta forma que muitos equívocos ocorressem.

Sob esse prisma reducionista herdado do paradigma cartesiano-newtoniano, a prática assistencial da saúde foi influenciada em inúmeros aspectos, entre eles 0 estabelecimento do diagnóstico pautado na classificação, no tratamento das doenças mentais com base na medicação e na hospitalização. Na ótica desse modelo, prevalece o fenômeno do adoecimento mental, que focaliza os sintomas, conflitos, problemas na comunicação e nas relações interpessoais. Esse contexto favoreceu o alicerce conceitual da ciência biomédica, ou seja, centrado na doença e desviado do ser humano na sua totalidade. A insuficiência das necessidades postas à psiquiatria, à proporção que dispõe a solucioná-las dentro desse modelo(1). Ainda, este paradigma está pautado na separabilidade ou na disjunção que se fundou excluindo o sujeito do conhecimento onde tudo é determinismo, não há sujeito, não há consciência e não há autonomia ${ }^{(2)}$.

$\mathrm{Na}$ legislação atual, Lei $\mathrm{n}^{0} 10.216$, constatamos expressivo avanço, legal, entretanto o mesmo não se alcança na prática de muitos serviços de atenção à saúde da população, uma vez que a assistência aos doentes mentais, no País, ainda é centrada no modelo hospitalocêntrico ${ }^{(3)}$. Lembramos também que os profissionais de saúde trabalham de maneira dicotômica, ou seja, mesmo com a legislação vigente e os progressos terapêuticos realizam uma assistência rígida e focada no transtorno mental, esquecendo a integridade e o contexto no qual o paciente está inserido. Imbuídos por hábitos construídos em tempos nos quais a melhora do paciente em sofrimento psíquico estava na negação da sua autonomia encontram dificuldades em dialogar com outros saberes, não percebendo a multidimensionalidade do ser humano no seu meio ambiente e na sua inserção familiar.

Assim, este estudo é uma reflexão teórica aliada às nossas vivências como enfermeiras/docentes em saúde mental. Convivendo com pessoas em sofrimento psíquico verificamos o sucateamento que persevera na psiquiatria em algumas instituições, mesmo que a política de saúde mental existente no Brasil busque a descentralização, a desinstitucionalização e a ressocialização desse indivíduo.

Precisamos repensar a insuficiência de uma assistência fragmentada que persiste em não ver 0 ser humano na sua integralidade da condição humana, seja na saúde ou na doença. Nesse sentido, faz-se um alerta sobre a importância de vê-lo em sua 
complexidade, pois o ser é ao mesmo tempo biológico e cultural e traz em si caracteres antagonistas de sábio e louco, trabalhador e lúdico, econômico e consumista, mas que inclusive também se dedica a danças, mitos, magias, crê nas virtudes, nutre-se dos conhecimentos comprovados, mas também de ilusões ${ }^{(4)}$.

Nessa perspectiva, objetivamos vislumbrar possibilidades de um novo paradigma onde o ser humano possa ser visto como um cidadão em sofrimento psíquico e não mais como uma doença. Respaldados pela compreensão histórica da psiquiatria, realizaremos algumas reflexões sobre os modelos tradicionais de assistência, ainda tão hegemônicos no país, bem como o fazer do enfermeiro, de maneira que possamos construir novas práticas na assistência ao indivíduo com transtorno mental.

\section{DO VELHO AO NOVO PARADIGMA DA PSIQUIATRIA}

Até a década de 70 do século passado, o sofredor psíquico foi rotulado como louco, agressivo e incapaz de conviver em sociedade. Em conseqüência disso, quando necessitava de cuidados, era encaminhado à internação hospitalar. Isso acontecia porque o modelo vigente de tratamento nesse período era realizado exclusivamente no hospital, sem a participação da família e da sociedade que não estavam inseridas no tratamento e na manutenção da saúde mental.

Os familiares, por descaso ou falta de suporte profissional e social, abandonavam seus entes na instituição. Com o passar do tempo, houve uma superlotação em vários hospitais psiquiátricos, levando os pacientes a dormirem onde encontrassem um lugar para deitar, sendo muitas vezes em condições inadequadas, precárias.

Esse fato pode ser comprovado em um estudo relatado na Revista Brasileira de Enfermagem, em 2003, onde as autoras descrevem a história vivenciada pelos pacientes em uma instituição psiquiátrica de saúde no Estado de Santa Catarina, entre as décadas de 40 e 60. Relatam que os pacientes dormiam em enfermarias com mais de cem leitos e, na falta dos mesmos, dormiam dois pacientes no mesmo leito. Também era comum encontrá-los dormindo no chão, o qual era denominado leito chão ${ }^{(5)}$. As autoras assinalam que, no período em que realizaram este estudo, foi possível perceber a forma de tratamento dispensada aos pacientes nessa instituição, bem como as condições de trabalho oferecidas aos funcionários que estavam aquém do ideal, pois perpetravam a política nacional assinalada pelo Governo Federal. Essa instituição, como muitas existentes no Brasil, mais asilava os pacientes e os excluía da sociedade do que os cuidava.

Nesse âmbito, "a institucionalização da doença mental produz a homogeneidade, objetiva e serializa todos aqueles que entram na instituição. (...) é construído um conjunto de formas de lidar, olhar, sentir o doente, a partir daquilo que se supõe ser louco e sua loucura"(6:79). Esse autor enfatiza em seus estudos que a instituição nega a subjetividade e a identidade do ser humano. 0 profissional não vê a pessoa doente, mas a doença e hábitos adquiridos. Somando-se a isto, esse modelo é "(...) centrado no problema-solução, doençacura é desconstruída no sentido de uma reinvenção da saúde, da existência sofrimento dos pacientes buscando a produção de vida"(7:21).

No Brasil, no final da década de 70 , esse modelo de assistência à saúde mental fundamentado na exclusão do ser humano do convívio social já apresentava sinais de esgotamento. Nesse sentido, faz-se necessário lembrarmos que os seres humanos são seres sociais e vivem o ser cotidiano em contínuas experiências individuais intransferíveis com o ser de outros. 0 que nos faz seres humanos é a maneira particular de vivermos juntos e sermos indivíduos, pessoas, somente enquanto somos seres sociais na linguagem. Para esse autor, 0 amor é fundamental porque nos permite escapar da alienação anti-social criada por nós através das nossas racionalizações. Recorda que é por meio da razão que justificamos a tirania ou o abuso sobre outros seres humanos. Vivemos na existência social, e sem o amor não ocorre socialização. Então, o fenômeno social humano está na aceitação e no respeito pelo outro(8).

Imbuídos da necessidade de mudança, os trabalhadores de saúde mental e de outros segmentos indignaram-se e divulgaram as péssimas condições às quais eram submetidos os pacientes nos hospitais psiquiátricos e solicitaram reformas urgentes no modelo assistencial. Mas foi em 1978 que se deu início a um movimento onde se buscava articular ações contra esse modelo de assistência ficando conhecido como Movimento de Trabalhadores em Saúde Mental. A partir dessa época, iniciaram-se algumas propostas de alterações no sistema asilar de assistência em saúde mental buscando locais alternativos de tratamento.

Em decorrência das transformações na área da psiquiatria, a enfermagem buscou inserir-se de maneira a oferecer um cuidado mais humanizado fundamentado nos princípios da Reforma Psiquiátrica, com base nos pressupostos da Reforma Sanitária e da Psiquiatria Democrática Italiana. Essa reforma iniciou a partir da seguinte pergunta: o que fazer com esses doentes mentais que passaram a vida dentro do hospital ${ }^{(9)}$ ? Partindo desta questão, a Reforma Psiquiátrica é um movimento que vem acontecendo a partir das transformações sociais e políticas no campo da psiquiatria desde 1980, principalmente na Itália, nos 
Estados Unidos e no Brasil. Esse movimento recebeu tal denominação por desencadear intensas transformações no contexto social, político, cultural e jurídico. Também porque busca a desinstitucionalização ou a desconstrução gradativa dos manicômios (instituições fechadas) e, portanto, a construção de novas alternativas de atenção à saúde mental pautada na lógica da cidadania.

No Brasil, os trabalhadores de saúde mental, sentindo a necessidade de discutir esse modelo excludente, organizaram-se e realizaram sucessivas Conferências de Saúde Mental em nível nacional, estadual, municipal e distrital, tendo como objetivo a inserção da Saúde Mental nas ações gerais de saúde. É importante salientar que nessas conferências 0 processo de municipalização, a criação dos conselhos de saúde e os dispositivos legais previstos para a efetivação do Sistema Único de Saúde (SUS) foram considerados como mecanismos na extinção do modelo asilar dos hospitais psiquiátricos.

Em 1987, os profissionais de saúde mental reuniram-se para realizar a I Conferência de Saúde Mental. Ainda não satisfeitos lançam nesse mesmo ano o tema Por uma sociedade sem manicômios no II Encontro Nacional de Trabalhadores em Saúde Mental.

Para muitos profissionais de saúde, gestores e familiares desistir de pensar que as doenças mentais eram causadas somente por fatores naturais e excluir os fatores sociais foi a maior dificuldade encontrada.

A II Conferência de Saúde Mental, em 1992, foi construída pela mobilização de distintos atores sociais. Os trabalhadores da área da saúde mental convencidos pela Luta Antimanicomial e articulados com a sociedade cívil e outros segmentos em nível nacional sentiram a necessidade de leis voltadas para as questões sociais de maneira a proporcionar um ambiente adequado para organizarem a reforma do sistema psiquiátrico. Eles buscavam uma assistência norteada pelos princípios da universalização, integralidade, eqüidade e da descentralização.

Nessa Conferência, foi resgatada a proposta do projeto do Deputado Paulo Delgado, de 1989, que já sinalizava a substituição progressiva do modelo hospitalocêntrico por serviços descentralizados, hierarquizados e diversificados nas práticas terapêuticas. Esse modelo preconiza a diminuição de internações e reinserção dessas pessoas à família e comunidade.

A partir destas conferências, vislumbram-se outras modalidades terapêuticas de trabalhar com 0 doente mental. 0 novo modelo, ou seja, a desinstitucionalização, deve estar sustentado nos princípios de inclusão, solidariedade, cidadania e da ética. Contudo, para que isso acontecesse eram necessárias profundas mudanças na equipe que atendia nos serviços de saúde mental. Esses profissionais, preocupados com a qualidade da assistência ao paciente, começaram a modificar as suas concepções no que tange ao respeito e ao direito destes pacientes de viverem em sociedade.

A desinstitucionalização já começava a apontar para a desconstrução do manicômio por meio de questionamentos do saber médico e da exclusão da psiquiatria, buscando alternativas no saber-fazer em saúde mental. A ação consistia numa desospitalização com fechamento gradativo dos hospitais psiquiátricos e a construção de serviços alternativos nos municípios e regiões.

Entretanto, foi somente após dez anos que a Lei $n^{0}$ 10.216 proposta pelo Deputado Paulo Delgado foi sancionada pelo Presidente da República em 06 de abril de 2001. Essa lei dispõe sobre a proteção e os direitos dos portadores de doença mental, redireciona o modelo assistencial em saúde mental não centrado no hospital psiquiátrico e também não permite a construção de novos hospitais. Para tanto, propunha a extinção progressiva dos manicômios e sua substituição por instituições abertas, tais como: Unidades de Saúde Mental em Hospital Geral, Emergência Psiquiátrica em Pronto-Socorro Geral, Unidade de Atenção Intensiva em Saúde Mental em regime de Hospital-Dia, Centro de Atenção Psicossocial (CAPS), Núcleos de Atenção Psicossociais (NAPS) que funcionariam por vinte e quatro horas, pensões protegidas, lares abrigados, centros de convivência, cooperativas de trabalho e outros serviços que preservem a integridade do cidadão. Ainda, identificamos nessa lei alguns benefícios em relação aos diferentes tipos de internação: a voluntária, quando é solicitada pelo paciente: a compulsória, quando é determinada pelo poder judiciário; a involuntária, quando necessita de um posicionamento por parte dos profissionais de saúde contrário ao desejo do paciente ${ }^{(3)}$.

Dessa forma, os objetivos desses serviços alternativos contrapõem-se ao modelo assistencial até então hegemônico, propondo-se a mudanças efetivas tanto no que se refere à organização de serviços quanto à assistência promovida em saúde mental. Desse modo, a ênfase está no sujeito e nas atividades coletivas priorizando grupos e oficinas terapêuticas onde as relações passam a ser individualizadas respeitando a história de cada um. As atividades terapêuticas constituem-se em fator de aglutinação das relações interpessoais, pois minoram a sintomatologia clínica do paciente. Todavia, esses serviços precisam ter condições necessárias para o funcionamento, como espaço, recursos materiais e humanos, bem como 
liberdade de expressão, respeitando as condições e escolhas do paciente ${ }^{(10)}$.

No entanto, as internações psiquiátricas continuam, apesar dos incentivos à desospitalização e dos benefícios no pagamento de procedimentos extra-hospitalares pelo SUS. Portanto, é desnecessária uma análise minuciosa para presumir que esse modelo ainda é encontrado em alguns municípios, mesmo naqueles onde já existem esses serviços alternativos. Com este enfoque, têm-se buscado criar e estruturar os diferentes tipos de serviços que podem ser oferecidos ao sofredor mental, bem como formar e reorientar uma prática assistencial direcionada para a reinserção social.

Assim, compreendemos que o ser humano é um ser ativo e reflexivo. A reflexão e a ação são duas dimensões fundamentais da humanidade concreta. Através do pensar/ refletir as idéias vão sendo elaboradas e reelaboradas num emergir de múltiplos entendimentos ${ }^{(11)}$.

\section{ROMPENDO O SILÊNCIO E RECONSTRUINDO SABERES EM ENFERMAGEM}

Na nossa trajetória profissional acompanhamos a evolução, de forma gradativa, da assistência em saúde mental prestada em diversas instituições de saúde. Reconhecemos hoje como aspectos positivos prestados ao cuidado as atividades sociorecreativas e culturais realizadas diariamente com os pacientes. Elas auxiliam na redução do preconceito existente acerca dessas pessoas e reforçam a idéia de que podem realizar diferentes atividades de acordo com as suas capacidades individuais. Destarte, com essa maneira de agir, produz-se a consciência da possibilidade do retorno ao convívio social e familiar.

Todavia, ainda notamos que a Enfermagem continua realizando uma assistência fragmentada, apresentando dificuldades em desenvolver atividades com os pacientes que não sejam aquelas realizadas dentro dos serviços psiquiátricos e de preferência que não tomem muito tempo. Por vezes, o profissional de enfermagem esquece que a estabilidade emocional do paciente será construída com a contribuição de todo o grupo multiprofissional e da família.

Cabe ressaltar que a nossa experiência profissional cotidianamente no ensino e na assistência evidencia que muitos dos profissionais de enfermagem percebem a melhora dos pacientes, porém relutam em integrar-se a esse novo paradigma do cuidado. Um dos fatores determinantes desta situação está na rotina dos trabalhadores de enfermagem em conviver quase que diariamente nos serviços de saúde mental e estarem expostos a diversos estressores. Os trabalhadores resistem à mudança, todavia não é a ela que eles se opõem, mas a uma situação imposta por lei ou pela própria instituição. Percebemos que seus processos naturais de mudança diferem das modificações ordenadas por leis ou reformas. Por isso, cremos que como enfermeiros/docentes possamos auxiliar a Enfermagem na medida em que compreendemos seus processos intrínsecos de mudança em espaços que reflitam a diversidade e a criatividade em grupos de apoio e de estudos, para que juntos possamos avançar na qualidade dos serviços, seja ao grupo de profissionais, seja ao paciente e sua família.

Mesmo reconhecendo que o profissional da enfermagem necessita do conhecimento técnico cognitivo-instrumental tão importante para desenvolver sua prática, compreendemos que isto não é tudo. A enfermagem precisa repensar os seus saberes e suas práticas. Devemos reavaliar nossa atitude, postura, ética, trabalho em grupo e valores. Portanto, é indispensável avaliarmos as nossas práticas a partir de uma perspectiva humana, sensível, reflexiva, crítica, criativa reconhecendo a especificidade e a objetividade de cada ser humano com quem interagimos. Nesse sentido, a assistência de enfermagem está atrelada ao conceito de doença à visão que se tem do homem (sadio ou não) na sociedade (12:19).

Para tanto, essa mudança requer dos profissionais de saúde uma visão que consiga fazer a relação entre a parte e o todo e do todo à parte. Porém não é uma tarefa fácil e também não é individual, pois necessita do intercâmbio entre todas as áreas que se encontram desagregadas para que se possa aprender concomitantemente a reunir o parcial ao global, o um ao múltiplo, a ordem à desordem, o observador ao observado. Portanto, esta é uma atitude que se opõe ao reducionismo e determinismo, mas associa as ações isoladas e compartimentadas trazendo um novo paradigma, o qual está pautado na ética da solidariedade, ou seja, numa ética que reúne o que está separado denominada complexidade ${ }^{(13)}$.

Como profissionais de enfermagem da área de saúde mental, percebemos ser ainda insuficiente as modificações ocorridas até o momento no Brasil. É necessário vislumbrar uma assistência que conceba o ser humano como um todo integrado e não como partes dissociadas, pois 0 modelo biomédico desconsidera os elementos físicos, psicológicos, sociais, culturais, ambientais, entre outros. Isto se coaduna, pelo menos com as idéias de que no âmbito do conhecimento, a mudança de um estado do saber a outro acontece com a incorporação de novos saberes, contemplando ou refutando os anteriores(... (14:45).

Corroborando essa idéia, denotamos que a saúde mental deve reunir os elementos desejados de bem- 
estar das pessoas e das ações imprescindíveis que possam gerar essa condição. Nesse sentido, a compreensão sobre a saúde mental passa a ser complexa à medida que contempla as dimensões psicológicas, sociais e psicossociais que determinam 0 processo saúde-doença ${ }^{(15)}$.

Sob essa perspectiva, a saúde na visão dos profissionais descentraliza-se da doença do indivíduo e faz-se um resgate de aspectos positivos, isto é, a atenção deixa de ser a doença e passa a ser o da reconstrução da vida. Com esse entendimento, o novo paradigma necessita de profissionais que dialoguem com outros atores, que sejam abertos a um novo saber e a uma nova abordagem no tratamento, valorizem 0 ser humano resgatando a sua história e sua vida cotidiana. Além disso, é imprescindível saber interpretar as diferentes linguagens que o corpo utiliza ao exteriorizar seus sentimentos.

0 enfermeiro é desafiado constantemente quando se posiciona diante da necessidade de rever conceitos, métodos e maneiras de lidar com o paciente com transtorno mental além da instituição manicomial. 0 abandono de certezas, verdades e conceitos para a solução dos problemas dá lugar à compreensão dos mesmos e conseqüentemente se evita a redução e a simplificação. Isso requer dos enfermeiros, além do conhecimento, a sensibilidade, criatividade e reflexão. Para tanto, (re)pensar a saúde mental urge compreendermos os princípios da complexidade, pois eles permitem 0 exercício da reflexão fundada na causalidade, contradição, ordem/desordem, certezas/incertezas, ambigüidade, interdisciplinaridade, autonomia, parte/ todo, singular/geral, responsabilidade, solidariedade, liberdade, emoções, sensibilidade, cidadania, qualidade de vida, entre outros. Por conseguinte, esse entendimento possibilita ao enfermeiro ampliar conhecimentos sem que haja reducionismo.

\section{Referências}

1. Roteli F, Leonardis O, Mauri D, Risio C. Desinstitucionalização: uma outra via. In: Nicácio F organizador. Desinstitucionalização. São Paulo(SP): Hucitec; 1990. p. 17-60.

2. Morin E. Ciência e consciência da complexidade. In: Morin E, Moigne JL. A inteligência da complexidade. $2^{\mathrm{a}}$ ed. São Paulo(SP): Peirópolis; 2000. p. 27-41.

3. Lei $n^{0} 10.216$ de 06 de abril de 2001. Dispõe sobre a proteção e os direitos das pessoas portadoras de transtornos mentais e redireciona o modelo assistencial em saúde mental. Diário Oficial da República Federativa do Brasil, Brasília(DF); 2001.

4. Morin E. A cabeça bem feita: repensar a reforma, reformar 0 pensamento. 10 ed. Rio de Janeiro(RJ): Bertrand Brasil; 2004.

\section{CONSIDERAÇÕES FINAIS}

A nossa vivência como enfermeiras/docentes reporta-nos ainda a uma realidade hospitalocêntrica, apesar dos inúmeros progressos com a Reforma Psiquiátrica. Esta realidade propicia percebermos a importância do enfermeiro voltado pra a compreensão das pessoas dentro do seu contexto social e familiar, assistindo-a na sua multidimensionalidade.

0 profissional precisa rever a maneira de lidar com os seres em sofrimento psíquico. Destacamos que se faz preciso um comprometimento constante dos trabalhadores de saúde mental em relação à desinstitucionalização, um cuidado centrado no ser humano que tem direito de ser assistido sem exclusão e a importância da consolidação da nossa prática em serviços alternativos para que efetivemos os princípios da universalização, integralidade, eqüidade e a descentralização. Portanto, exige-se dos profissionais de enfermagem novas formas de assistir as pessoas em sofrimento psíquico.

0 louco tem carregado o estigma da periculosidade e da exclusão durante todos esses anos e como conseqüência obteve 0 isolamento e daí 0 asilamento. 0 resultado dessa maneira de lidar com a loucura foi por muitos anos a reprodução de sujeitos para os quais foi negado o direito de serem cuidados como cidadãos. Assim, o novo paradigma implica abandonar os princípios de separabilidade, ordem e lógica, porém unir as partes à totalidade, ou seja, integrá-lo(2).

Precisamos de um pensamento que trate com a incerteza, que seja apto a reunir, contextualizar, globalizar, mas também saiba reconhecer o singular, 0 individual e o concreto. Portanto, o pensamento que afronta a incerteza pode esclarecer a ética da reunião, da solidariedade e da compreensão humana.

5. Borenstein MS, Pereira VP, Ribas DL, Ribeiro AAA. Historicizando a enfermagem e os pacientes em um hospital psiquiátrico. Rev Bras Enferm 2003; 56 (2): 201-05.

6. Spricigo JS. Desinstitucionalização ou desospitalização: a aplicação do discurso na prática psiquiátrica de um serviço de Florianópolis. Teses em Enfermagem, 42. Florianópolis(SC): PEN/ UFSC; 2002.

7. Vasconcelos E. Desinstitucionalização e interdisciplinaridade em saúde mental. Cad IPUB 1997; (7): 19-43.

8. Maturana H. Emoções e linguagem na educação e na política. $3^{\mathrm{a}} \mathrm{ed}$. Belo Horizonte(MG):UFMG; 2002.

9. Serrano Al. A criação do CAPS de Florianópolis (SC). Entrevista. Florianópolis; 2001.

10. Tavares CMM, Barone AM, Fernandes JC, Moniz MA. Análise de implementação de tecnologia de cuidar em saúde mental na perspectiva da atenção psicossocial. Esc Anna Nery Rev Enferm 2003; 7 (3): 342-50. 
11. Chanlat JF. Uma visão do sofrimento humano nas organizações. In: Chanlat, JF (coord.). 0 indivíduo na organização: dimensões esquecidas. Tradução e adaptação Arakcy M. Rodrigues. São Paulo: Atlas, 1992.

12. Furegato RFF. Relações interpessoais terapêuticas na enfermagem. Ribeirão Preto(SP): Scala; 1999.

13. Morin E. Introdução ao pensamento complexo. Porto Alegre(RS): Sulina; 2005.

14.Tarride Ml. Saúde pública: uma complexidade anunciada. Rio de Janeiro(RJ): Ed da FIOCRUZ; 1998.

15. Saraceno B. Libertando identidades: da reabilitação psicossocial à cidadania possível. Belo Horizonte(MG): Te Cora; 1999.

\section{Sobre as Autoras}

\section{Marlene Gomes Terra}

Enfermeira, Mestre em Educação, Professora Assistente da Universidade Federal de Santa Maria - UFSM, Santa Maria-RS. Membro do Grupo de Pesquisa Cuidado, Saúde e Enfermagem - UFSM. Doutoranda do Programa de Pós-Graduação em Enfermagem da Universidade Federal de Santa Catarina - UFSC, Florianópolis. Membro do Grupo de Estudos sobre Cuidado e Saúde de Pessoas Idosas GESPI. Bolsista CAPES/PQI. E-mail: martesm@terra.com.br.

\section{Dorotéa Loes Ribas}

Enfermeira, Mestre em Enfermagem, Aluna especial da disciplina Tópico Avançado em Pesquisa: A Complexidade na construção do conhecimento segundo Morin do Curso de Doutorado em Enfermagem da Universidade Federal de Santa Catarina - UFSC. Membro Efetivo do Grupo de Estudos de História do Conhecimento da Enfermagem (GEHCE). E- mail: dorotearibas@hotmail.com

\section{Fernanda Sarturi}

Enfermeira, Especialista em Administração dos Serviços de Saúde, Professora Substituta do Departamento de Enfermagem e Membro do Grupo de Estudos e de Pesquisas em Gestão em Enfermagem e Saúde da Universidade Federal de Santa Maria - UFSM/RS. E-mail: fernandasarturi@yahoo.com.br

\section{Alacoque Lorenzini Erdmann}

Professora Titular do Departamento de Enfermagem da Universidade Federal de Santa Catarina - UFSC, Docente do Programa de PósGraduação e do Departamento de Enfermagem, Doutora em Filosofia da Enfermagem. Pesquisadora e Representante da Área de Enfermagem no CNPq. Coordenadora do Grupo de Estudos e Pesquisas em Administração de Enfermagem e Saúde GEPADES UFSC.E-mail: alacoque@newsite.com.br 